\title{
A Case Study on Idiopathic Orbital Pseudotumor: Surgery and Steroid Treatment
}

\author{
Jian-Feng Zhu ${ }^{1}$, Wei-Jiao Zhan ${ }^{1}$, Li-Hua Wang ${ }^{2}$ and Yan-Hong Wang ${ }^{3 *}$ \\ ${ }^{1}$ Department of Ophthalmology, Linyi municipal hospital, Linyi $276003,{ }^{2}$ Department of Ophthalmology, Provincial Hospital \\ affiliated to Shandong University, Jinan 250021, ${ }^{3}$ Department of Ophthalmology, Women \&children's health care hospital of \\ Linyi, Jinan 276016, China
}

*For correspondence: Email: wanglhglasses@gmail.com; Tel/Fax: 0086-539-8125509

Received: 15 April 2015

Revised accepted: 4 October 2015

\begin{abstract}
This is a case study of five isolated orbital nerve inflammatory pseudotumor cases presenting with protrusion and visual acuity of the right eye. Optic disk edema was observed by ophthalmoscopy. Plain and contrast-enhanced magnetic resonance imaging (MRI) were used to examine the orbital fat and enlargement of the right optic nerve sheath along with orbital magnetic resonance imaging diagnostic test. The visual acuity (VA) of all the admitted patients was 1.5/20. All the patients reported attacks of retrobulbar pain and severe headache at fairly regular intervals. The patients on clinical examination were found to have protrusion, reduced visual acuity of the right eye with an ipsilateral afferent pupillary defect. There was no motility of the right eye and the exophthalmos of the right part was $27 \mathrm{~mm}$. On examination, patients were diagnosed to have idiopathic orbital inflammation and received steroid therapy for 6 months. Thereafter, patients received surgical treatment to remove the superior wall of the orbit followed by cortisone therapy for a further 6 months. The follow-up examination of the patients for one year revealed a gradual improvement in the vision of all the patients. The VA of the right eye for all the patients was 6/20, and the exophthalmos was now around $19 \mathrm{~mm}$. Thus, a dramatic response to surgery and steroid treatment was observed in all the patients.
\end{abstract}

Keywords: Orbital fat, Visual acuity, Optic disk edema, Optic nerve, Cortisone therapy

Tropical Journal of Pharmaceutical Research is indexed by Science Citation Index (SciSearch), Scopus, International Pharmaceutical Abstract, Chemical Abstracts, Embase, Index Copernicus, EBSCO, African Index Medicus, JournalSeek, Journal Citation Reports/Science Edition, Directory of Open Access Journals (DOAJ), African Journal Online, Bioline International, Open-J-Gate and Pharmacy Abstracts

\section{INTRODUCTION}

Idiopathic orbital pseudotumor (IOP) is an inflammation arising due to nongranulomatous orbital mass [1] and accounts for $4.7-6.3 \%$ of all orbital disorders [2,3]. It is usually observed after 45 years of age [4]. After thyroid ophthalmopathy and lymphoproliferative disorders, IOP is the third commonly observed orbital disease. The histopathological examination of IOP revealed the presence of fibro inflammatory infiltrate and lesions with atypical histopathologic patterns [2]. It is found in the orbit where main target is the lacrimal gland [4]. IOP is mostly unilateral $[1,4]$ and the symptoms include diplopia, conjunctival chemosis, visual disability and restriction of extraocular muscle function [4]. IOP comprises different categories of orbital inflammatory diseases involving various levels of orbital contents. The optic nerve may be affected as a part of the posterior segment process [5]. Isolated optic nerve is very rarely involved and has been shown to be involved in one patient out of 16 cases of orbital pseudotumor by Peyster et al [6].

The inflammatory process may affect different orbital structures like the globe, extraocular 
muscles, lachrymal glands and the optic nerve [7]. Deposition of fibro collagen over the affected nerve/ sheath complex leads to diffuse enlargement of the optic nerve [8-10]. Idiopathic orbit inflammatory pseudotumor is usually associated with other diseases, including, Tolosa Hunt syndrome, pituitary histiocytosis, idiopathic meningitis, carotido-cavernous fistula, Wegener granulomatosis and Erdheim-Chester disease $[11,12]$. The study was performed to investigate the efficacy of surgical extraction of the superior wall of orbit followed by cortisone therapy for 6 months in the improvement of vision of patients with protrusion and visual acuity.

\section{EXPERIMENTAL}

\section{Patient}

Five patients, 3 men and 2 women (average age 53 year) with more than one-year history of progressive protrusion and reduced vision of the right eye were admitted to our hospital (Figure 1). The visual acuity (VA) of all the patients was $1.5 / 20$.

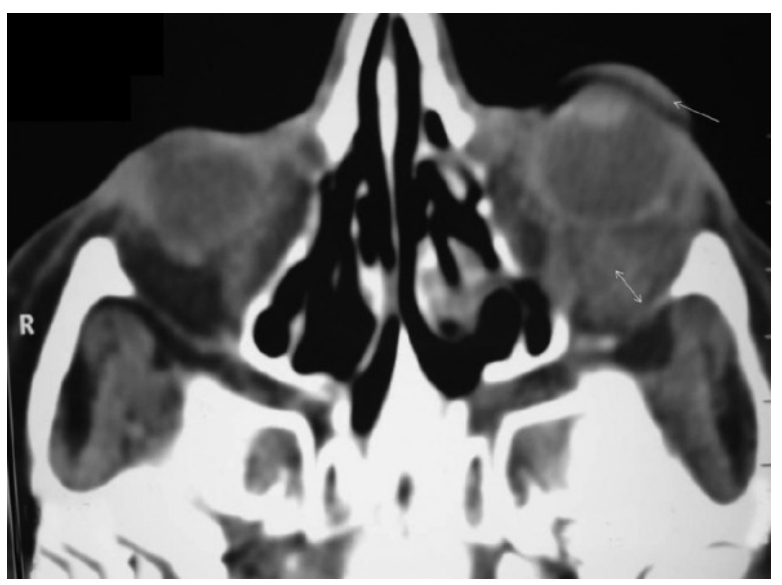

Figure 1: Pre-treatment-Contrast enhanced CT scan of orbit axial view showing anterior displacement of the right globe (arrow) and non-enhancing soft tissue mass in the right orbit (double arrow)

Careful examination of the patients revealed absence of any trauma to the orbit. All the patients reported attacks of retrobulbar pain and severe headache after regular intervals. The patients on clinical examination were found to have protrusion of the right eye, reduced visual acuity of the right eye with an ipsilateral afferent pupillary defect. There was no motility of the right eye and the exophthalmos of the right part measured $27 \mathrm{~mm}$. We also observed a central scotoma and poor color perception in all the patients. Optic disk edema was observed on examination by Ophthalmoscopy. Serum levels of antinuclear antibody were normal. However, diffuse extra- and intraconal mass infiltrating the orbital fat and enlargement of the right optic nerve sheath of the orbit in all the patients was clearly seen. The cavernous sinuses and the brain were normal. On examination patients were diagnosed to have idiopathic orbital inflammation and received steroid therapy for six months. Following chemotherapeutic treatment patients underwent surgery for extraction of superior wall of the orbit. After surgery cortisone therapy was continued for six months more. Follow-up examination of all the patients for one year revealed improvement in the vision. The VA (Functional Vision Analyzer from Stereo Optical Company, Inc. Chicago, United States) of the right eye for all the patients was $5 / 20$, and the exophthalmos was measured to be around 19 $\mathrm{mm}$ (Figures 2, 3).

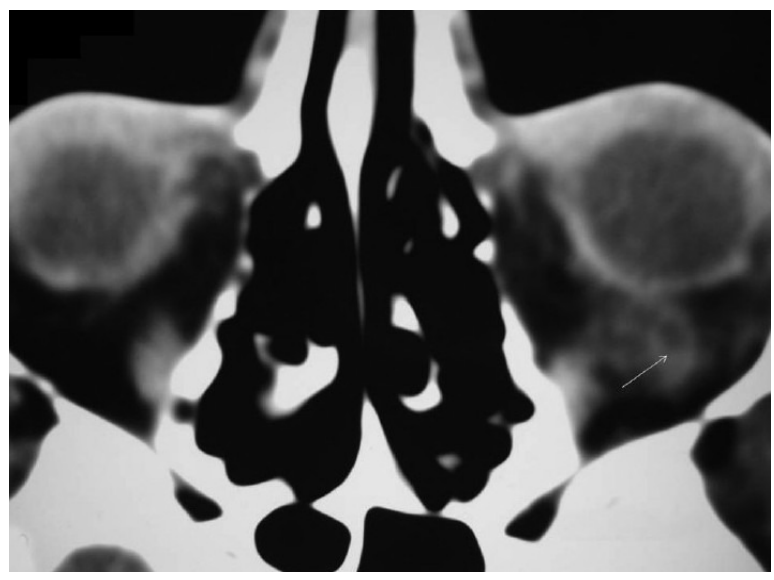

Figure 2: After 6 months of starting steroid therapy contrast enhanced CT Scan of right orbit axial view showing partial resolution of the soft tissue mass

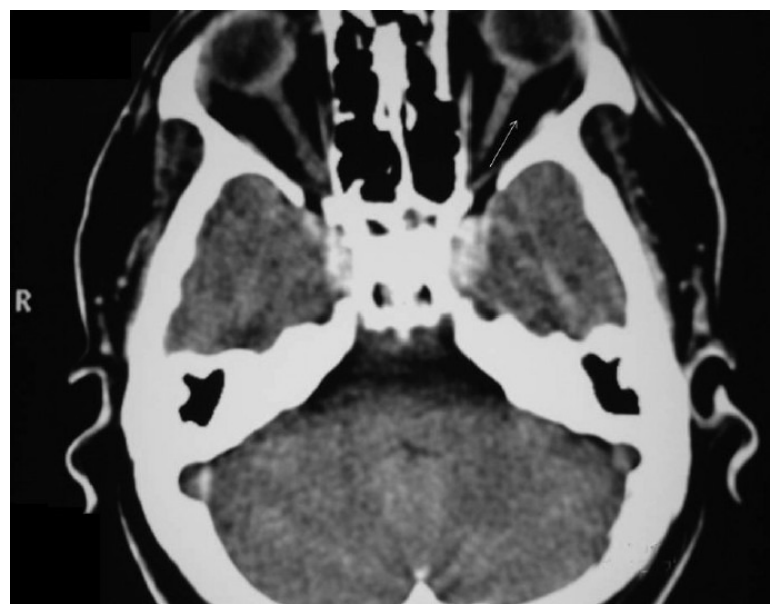

Figure 3: After 1 year of treatment- contrast enhanced CT scan of orbit- axial view showing complete resolution of proptosis and soft tissue mass 
Dense fibrous proliferations, with collagen deposition, infiltrating the muscles were observed during histopathological examination of the biopsy. Numerous inflammatory cells were observed, consisting mainly of lymphocytes, diffusely disposed or arranged in follicles with germinal centers. Plasma cells, macrophages and scattered neutrophils were also observed. A granulomatous inflammatory reaction was present in some areas, with epithelioid cells and giant multinucleated cells.

\section{DISCUSSION}

Idiopathic orbital pseudotumor is associated with symptoms similar to many other intraorbital tumors [8] making the diagnosis difficult. Image findings are very useful for the characterization of the inflammatory process level. In IOP the commonly observed features include retro-orbital fat infiltration, proptosis, extraocular muscle enlargement and enhancement, orbital apex inflammation and optic nerve thickening [13]. Edematous enlargement of the optic nerve in the perineuritic form of the disease is shown by computer tomography (CT) and magnetic resonance imaging (MRI). The optic nerve/sheath complex enlargement is caused by the neoplastic and non-neoplastic conditions [10]. The neoplastic causes include optic gliomas, meningiomas, neurofibromas, hemangioblastomas, metastases, leukemias and lymphomas. On the other hand, non-neoplastic causes include Optic neuritis, pseudotumours, granulomatous optic neuropathies (most commonly sarcoidosis), dysthyroid orbitopathies, traumatic hematomas and optic nerve drusen.

Optic nerve drusen is associated with pseudopapilloedema and deposition of calcium between the optic nerve and globe. In the present study, tumor cases were excluded because of absence of the optic canal enlargement [14], hyperostosis and calcification [15-17]. However the symptoms of orbital pain and headache were considered to be of inflammatory etiology [10-14]. Finally, the results from surgery of the orbit and the response to a therapeutic trial of steroids clinched the diagnosis in favor of inflammatory pseudotumor [18-21].

\section{CONCLUSION}

Surgical extraction of the superior wall of orbit followed by cortisone therapy for 6 months improved the vision of patients with protrusion and visual acuity of the right eye. Thus, the strategy can be used for treatment of the patients with orbital protrusion and visual acuity.

\section{REFERENCES}

1. Medenhall WM, Lessner AM. Orbital pseudotumor. Am J Clin Oncol 2010; 33: 304-306.

2. Swamy BN, McCluskey $P$, Nemet A, Crouch R, Martin P, Benger $R$, et al. Idiopathic orbital inflammatory syndrome: clinical features and treatment outcomes. Br J Ophthalmol 2007; 91: 1667-1670.

3. Carruth BP, Wladis EJ. Inflammatory modulators and biologic agents in the treatment of idiopathic orbital inflammation. Curr Opin Ophthalmol 2012; 23: 420426.

4. Ding ZX, Lip G, Chong V. Idiopathic orbital pseudotumor. Clin Radiol 2011; 66: 886-892.

5. Mombaerts I, Goldschmeding $R$, Schlingemann RO, Koornneef L. What is orbital pseudotumor? Surv Ophthalmol 1998; 41: 66-78.

6. Peyster RG, Hoover ED, Hershey BL, Haskin ME. High resolution CT of lesions of the optic nerve, AJR Am J Roentgenol 1983; 140: 869-74.

7. Mafee MF, Schatz CJ. The orbit. In: Som PM, Bergeron $R T$, Curtin HD, Reede DL (eds), Head and neck imaging, 2nd edition, Mosby-Year Book, St. Louis 1991; pp 783-788.

8. Rootman J, McCarthy M, White V, Harris G, Kennerdell J. Idiopathic sclerosing inflammation of the orbit. $A$ distinct clinicopathologic entity, Ophthalmology 1994; 101: $570-584$

9. Swamy BN, McCluskey $P$, Nemet $A$, Crouch $R$, Martin $P$, Benger $R$, Ghabriel $R$, Wakefield D. Idiopathic orbital inflammatory syndrome: clinical features and treatment outcomes, $\mathrm{Br} J$ Ophthalmol 2007; 91: 1667-1670.

10. Yuen SJ, Rubin PA, Idiopathic orbital inflammation: distribution, clinical features, and treatment outcome, Arch Ophthalmol 2003; 121: 491-499.

11. Lutt JR, Lim LL, Phal PM, Rosenbaum JT, Orbital inflammatory disease, Semin Arthritis Rheum 2008; 37: 207-222.

12. Gordon LK, Orbital inflammatory disease: a diagnostic and therapeutic challenge, Eye (Lond) 2006; 20: pp 1196-1206.

13. Mafee MF, Schatz CJ, The orbit. In: Som PM, Bergeron $R T$, Curtin $H D$, Reede $D L$ (eds), Head and neck imaging, 2nd edition, Mosby-Year Book, St. Louis 1991; 783-788.

14. Weber AL, Jakobiec FA, Sabates NR, Pseudotumor of the orbit, Neuroimaging Clin N Am 1996; 6: 73-92.

15. Chaudhry IA, Shamsi FA, Arat YO, Riley FC, Orbital pseudotumor: distinct diagnostic features and management, Middle East Afr J Ophthalmol 2008; 15:17-27.

16. Nugent RA, Rootman J, Robertson WD, Lapointe JS, Harrison PB. Acute orbital pseudotumors: classification and CT features, AJR Am J Roentgenol 1981; 137:957-962.

17. Atlas SW, Galeta SL, Orbit and visual system. In: Atlas SW (Ed), Magnetic resonance imaging of the brain

Trop J Pharm Res, November 2015; 14(11): 2137 
and spine, 2nd edition, Lippincott-Raven Publishers, Philadelphia 1999; pp 1007-1092.

18. Borruat FX, Vuilleumier $P$, Ducrey $N$, Fankhauser $H$, Janzer RC, Regli $F$, Idiopathic orbital inflammation (orbital inflammatory pseudotumour): an unusual cause of transient ischaemic attack, J Neurol Neurosurg Psychiatry 1995; 58: 88-90.
19. Friberg TR, Stewart T, Ocular involvement in systemic idiopathic fibrosis, Retina 1983; 3: 34-39.

20. Curtin HD. Pseudotumor, Radiol Clin North Am 1987; 25: 583-599.

21. Lewis PM. Inflammatory pseudotumor of the orbit: report of a case, Trans Am Ophthalmol Soc 1937; 35: 328335. 